\title{
Kikuchi-Fujimoto Disease Heralding Systemic Lupus Erythematosus
}

Jonathan A. Aun, DO; Matthew J. Hubbard, DO

From the Department of

Internal Medicine at the Uniformed Services University of the Health Sciences and the Department of Cardiology

at Walter Reed National

Military Medical Center in Bethesda, Maryland (Dr Aun)

and the Department of

Rheumatology at Keesler Medical Center at Keesler Air Force Base in Biloxi,

Mississippi (Dr Hubbard).

Disclaimer: The views represented in this manuscript are solely those of the authors and do not reflect the official policy or position of the United

Sates Air Force, Department of Defense, or the US Government.

Financial Disclosures: None reported.

Support: None reported. Address correspondence to Jonathan A. Aun, DO, Walter Reed National Military Medical Center, Department of Cardiology, 104 Wood Road, Bethesda, MD 20889-0001.

Email: jonathan.a.aun.mil@mail.mil

Submitted May 11, 2020; revision received July 10, 2020; accepted July $13,2020$.

\author{
In this case report, the authors discuss a patient with a rare entity, Kikuchi \\ Fujimoto Disease, which exhibited unique osteopathic structural examination \\ findings, including enlarged cervical lymph nodes in conjunction with a \\ Chapman reflex (CR). This report highlights the critical importance of histo- \\ logical examination of the lymph nodes. Additionally, it reminds physicians \\ to consider the ways in which $\mathrm{CR}$ can potentially contribute to the diagnostic \\ process. \\ J Am Osteopath Assoc. 2020;120(12):934-939. Published online October 5, 2020. \\ doi:10.7556/jaoa.2020.137 \\ Keywords: autoimmune, lymph nodes, physical examination, systemic lupus erythematosus
} ikuchi-Fujimoto disease (KFD), or histiocytic necrotizing lymphadenitis, is a perplexing benign and self-limited syndrome of unknown etiology. ${ }^{1,2}$ Evolving over weeks, this condition presents itself with predominantly posterior cervical lymphadenopathy and constitutional symptoms. ${ }^{1,2}$ It generally affects women of Asian descent in early adulthood and can precede, follow, or occur concurrently with the diagnosis of systemic lupus erythematosus (SLE). ${ }^{2-3}$ We present a patient with this rare enigmatic constellation of symptoms, which highlights the key role of histological examination of the lymph nodes for a timely diagnosis. Moreover, we illustrate the potential contributions of $\mathrm{CR}$ to the diagnostic process for underlying visceral dysfunction..

\section{Report of Case}

In late summer 2017, a 21-year-old African American woman without previous medical problems or sexual activity presented with 6 weeks of intermittent high-grade fevers, painful vulvar lesions, 20-lb weight loss, fatigue, and malaise. At symptom onset, she experienced tender acneiform-like nodules on the face and sternum, and painful blistering of the lower lip that had healed by time of presentation. Physical examination revealed a cachectic woman with a disheveled appearance. There was no evidence of iritis or uveitis, though bilateral retinal vasculitis with small focal areas of retinal hemorrhage were visualized on ophthalmological examination. Oral examination did not reveal any aphthous ulcers, though dry mucous membranes were discovered. There was no alopecia. A careful palpatory evaluation was performed in conjunction with a 30-second Chapman's reflex (CR) visceral screening examination. ${ }^{4}$ Notable findings included anterior cervical and inguinal lymphadenopathy. Lymph nodes were painful, warm, and moderately enlarged, measuring approximately 1 to $2 \mathrm{~cm}$. She was also found to have multiple vulvar ulcerations. The 30 -second visceral screening examination was without acute findings. Given the patient's lymphadenopathy of the neck, the physician (J.A.) decided to 


\begin{tabular}{|c|c|c|c|c|}
\hline Location & Palpation & Pain & Confirmation & $\begin{array}{c}\text { Visceral } \\
\text { Dysfunction }\end{array}$ \\
\hline $\begin{array}{l}\text { Deep to skin } \\
\text { - Subcutaneous } \\
\text { areolar tissue, } \\
\text { most often } \\
\text { lying on the } \\
\text { deep fascia or } \\
\text { periosteum }\end{array}$ & $\begin{array}{l}\text { - Gangliform } \\
\text { - Edematous } \\
\text { - Ridge-like } \\
\text { or ropy } \\
\text { - Fibrospongy } \\
\text { - Shotty } \\
\text { - Varies in } \\
\text { size from a } \\
\text { "BB" pellet } \\
\text { to a pea, or } \\
\text { from a } \\
\text { pinhead to } \\
\text { an almond }\end{array}$ & $\begin{array}{l}\text { - Patient } \\
\text { endorses } \\
\text { tenderness } \\
\text { from } \\
\text { slightly } \\
\text { painful to } \\
\text { almost } \\
\text { unbearable } \\
\text { pain } \\
\text { - Some may } \\
\text { show no } \\
\text { tenderness } \\
\text { - No } \\
\text { radiation } \\
\text { endorsed }\end{array}$ & $\begin{array}{l}\text { - Anterior } \\
\text { CR should } \\
\text { be used for } \\
\text { diagnostic } \\
\text { purposes } \\
\text { - Once } \\
\text { positive } \\
\text { anterior CR } \\
\text { established, } \\
\text { its diagnosis } \\
\text { is confirmed } \\
\text { through the } \\
\text { presence of } \\
\text { a posterior } \\
\text { CR }\end{array}$ & $\begin{array}{l}\text { Types of visceral } \\
\text { dysfunction believed } \\
\text { to cause positive CR } \\
\text { are: } \\
\text { - inflammation } \\
\text { - spasm } \\
\text { - distention of } \\
\text { the viscera }\end{array}$ \\
\hline
\end{tabular}

Figure 1.

Characteristics of Chapman reflex $(\mathrm{CR})^{4}$

evaluate for specific CR corresponding to this region of the body. The physician applied firm digital pressure to the right medial humerus. The soft tissue in this area was both edematous and ropy, measuring about the size of an almond. The area overlying this CR was granular in quality and accompanied by slight pain endorsed by the patient without radiation. Given establishment of the positive anterior CR, a posterior CR was palpated for confirmation. Similar findings were demonstrated at the left transverse process of T3-T5, though pain was less intense. No radiation of pain was endorsed by the patient. Given the location in the soft tissue, palpatory quality, and distinct pain characteristics, a CR was validated (Figure 1). ${ }^{4}$

Initial screening labs were obtained (Table). Computed tomography (CT) of the patient's neck revealed enlargement of multiple cervical lymph nodes, including an enlarged right supraclavicular lymph node and a right level $2 \mathrm{~b}$ node, demonstrating a low-density center concerning for a neoplastic process (Figure 2). An excisional cervical lymph node biopsy was performed with simultaneous biopsies of the vulvar ulcerations and nodular skin lesion overlying the sternum. Histology of the right cervical lymph node revealed architecture distorted by large areas of histiocytes with prominent karyorrhectic debris (Figure 3). Histiocytes were noted to have abundant pink cytoplasm and frequent crescent-shaped nuclei in combination with a paucity of neutrophils and eosinophils. Other areas of the lymph node had mildly expanded paracortical T-cell zones with scattered immunoblasts and plasma cells. By paraffin immunohistochemistry, the histocytes were positive for CD68, CD163, and myeloperoxidase. CD123 highlighted an increased number of plasmacytoid dendritic cells present singly and in discrete aggregates. Findings were consistent with KFD; however, lupus lymphadenitis (LL) was also considered histologically.

Shave biopsy of the left posterior labia minora was noted to have brisk dermal neutrophilic infiltrate; sebaceous glands were noted to be very edematous (Figure 4). These histologic findings were not specific. Flow cytometry was negative, and malignancy was excluded. Rheumatologic work up revealed positive serologies for antinuclear antibody (ANA), anti-Smith antibody, and low complement. A positive ribonucleoprotein (RNP) was also noted (Table). Pathergy test was negative. Infectious etiologies were considered but ruled out based on absence of positive laboratory findings or blood cultures. Rheumatic conditions considered 
Table.

Laboratory Analysis Results

\begin{tabular}{|c|c|c|}
\hline Laboratory analysis & Value & $\begin{array}{l}\text { Reference } \\
\text { range }\end{array}$ \\
\hline Hemoglobin & $7.2 \mathrm{~g} / \mathrm{dL}$ & $12.0-15.0 \mathrm{~g} / \mathrm{dL}$ \\
\hline Hematocrit & $22.3 \%$ & $36.0-48.0 \%$ \\
\hline MCV & $76.8 \mathrm{fL}$ & 79.0-100.0 fL \\
\hline Serum iron & $12 \mathrm{mcg} / \mathrm{dL}$ & $50-170 \mathrm{mcg} / \mathrm{dL}$ \\
\hline Iron binding capacity & 199 mcg/dL & $112-346 \mathrm{mcg} / \mathrm{dL}$ \\
\hline Iron saturation & $6.0 \%$ & $15-50 \%$ \\
\hline Transferrin & $155 \mathrm{mg} / \mathrm{dL}$ & $200-360 \mathrm{mg} / \mathrm{dL}$ \\
\hline Ferritin & $20.8 \mathrm{ng} /$ & 8-388 ng/mL \\
\hline ESR & $97 \mathrm{~mm} / \mathrm{hr}$ & $0-20 \mathrm{~mm} / \mathrm{hr}$ \\
\hline CRP & $4.09 \mathrm{mg} / \mathrm{dL}$ & $0-0.29 \mathrm{mg} / \mathrm{dL}$ \\
\hline Complement C3 & $125 \mathrm{mg} / \mathrm{dL}$ & $82-167 \mathrm{mg} / \mathrm{dL}$ \\
\hline Complement C4 & $13 \mathrm{mg} / \mathrm{dL}$ & $14-44 \mathrm{mg} / \mathrm{dL}$ \\
\hline 24 hour urine protein & $191.3 \mathrm{mg} / \mathrm{dL}$ & $0-150 \mathrm{mg} / \mathrm{dL}$ \\
\hline $\begin{array}{l}\text { Nuclear antibody } \\
\text { screen (ANA) }\end{array}$ & $\begin{array}{l}1: 80, \\
\text { Speckled } \\
\text { Pattern }\end{array}$ & \\
\hline Rheumatoid factor & $10.7 \mathrm{IU} / \mathrm{ml}$ & $0-15 \mathrm{IU} / \mathrm{ml}$ \\
\hline Smith extractable $A b$ & $1.2(\mathrm{H}) \mathrm{Al}$ & $0.0-0.9 \mathrm{Al}$ \\
\hline Ribonucleoprotein Ab & $4.9(\mathrm{H}) \mathrm{Al}$ & $0.0-0.9 \mathrm{Al}$ \\
\hline Antichromatin Ab & $<0.2 \mathrm{Al}$ & $0.0-0.9 \mathrm{Al}$ \\
\hline SS-A Ab & $<0.2 \mathrm{Al}$ & $0.0-0.9 \mathrm{Al}$ \\
\hline SS-B Ab & $<0.2 \mathrm{Al}$ & $0.0-0.9 \mathrm{Al}$ \\
\hline Anti-DNA (DS) & $1 \mathrm{IU} / \mathrm{mL}$ & $0-9 \mathrm{IU} / \mathrm{mL}$ \\
\hline DRVVT & $45.5 \mathrm{Sec}$ & $0.0-47.0 \mathrm{sec}$ \\
\hline Jo-1 extractable Ab & $<0.2$ Units & $<20$ Units \\
\hline Aldolase & $5.7 \mathrm{U} / \mathrm{L}$ & $3.3-10.3 \mathrm{U} / \mathrm{L}$ \\
\hline HLA-B27 & Absent & \\
\hline Pathergy test & Negative & \\
\hline Proteinase 3 Ab (PR3) & $0.5 \mathrm{U} / \mathrm{mL}$ & \\
\hline $\begin{array}{l}\text { Myeloperoxidase } \\
\text { (MPO) }\end{array}$ & $1.1 \mathrm{U} / \mathrm{mL}$ & \\
\hline SCL-70 extractable Ab & $<0.2$ Units & \\
\hline
\end{tabular}

included KFD, SLE, subacute cutaneous lupus erythematosus (SCLE), Behcet's disease, mixed connective tissue diseases, and periodic fever syndrome.

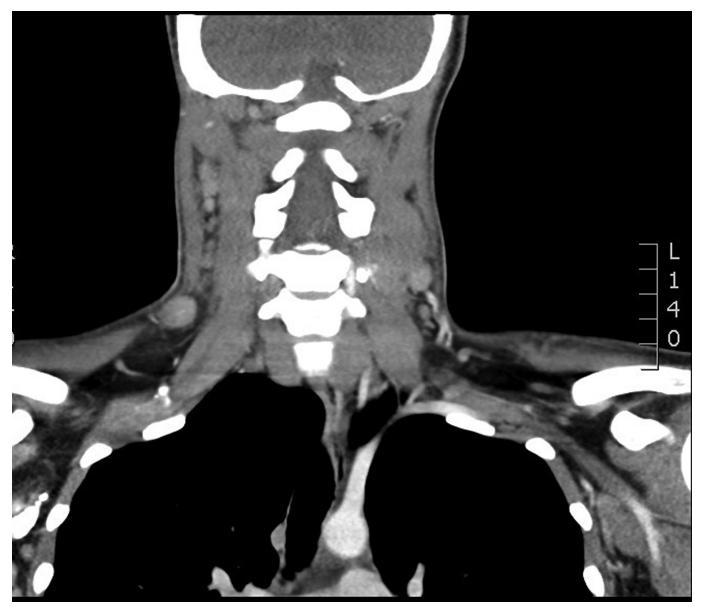

Figure 2.

The patient's head and neck CT revealed mild interval enlargement of multiple cervical lymph nodes, which were more prominent on the right. This image shows a right level $2 \mathrm{~b}$ lymph node measuring approximately $1.6 \times 1.0 \mathrm{~cm}$ with low density center, likely necrotic, and a right supraclavicular lymph node measuring $1.4 \times 1.0 \times 1.4 \mathrm{~cm}$ (axial image 41 and coronal image 44).

Given the histological findings on biopsy in correlation with the patient's physical exam and history, a provisional diagnosis of KFD was made, and she was treated with colchicine, hydroxychloroquine, and prednisone, resulting in improvement of her symptoms. At follow up 5 months after presentation, she was found to have new nonscarring alopecia and lymphopenia, further indicating systemic lupus erythematosus (SLE) based on 2012 diagnostic criteria and new diagnostic criteria published by the European League Against Rheumatism (EULAR) and the American College of Rheumatology (ACR) in 2019. 5,6

\section{Discussion}

KFD is a rare syndrome presenting with nonspecific symptoms and characterized by regional necrotizing lymphadenitis. It is usually a benign and self-limited disease process, but may be a harbinger for the onset of SLE. Published reviews estimate that $30 \%$ of KFD cases will develop SLE and that it will occur 


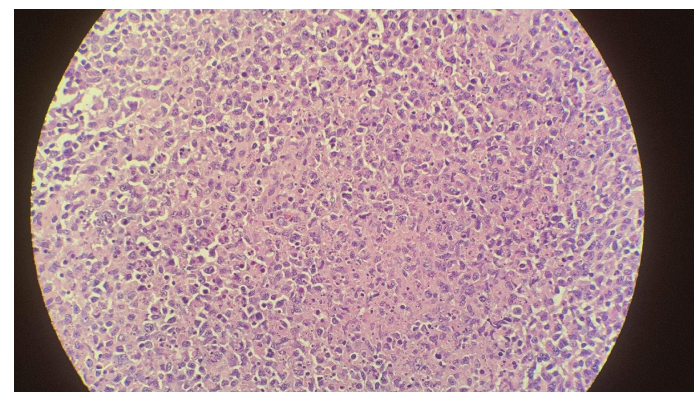

Figure 3.

This image shows the results of lymph node, right cervical biopsy. Histiocytes were noted to have abundant pink cytoplasm and frequent-crescent shaped nuclei in combination with a paucity of neutrophils and eosinophils. Other areas of the lymph node had mildly expanded paracortical T-cell zones with scattered immunoblasts and plasma cells. By paraffin immunohistochemistry, the histocytes were positive for CD68, CD163, and myeloperoxidase. CD123 highlighted an increased number of plasmacytoid dendritic cells present singly and in discrete aggregates. Findings were consistent with Kikuchi-Fujimoto disease; however, lupus lymphadenitis (LL) was also considered histologically.

concurrently with or after SLE presentation in $47 \%$ and $23 \%$ of cases, respectively. ${ }^{1-3}$ Clinical reviews have postulated that KFD may be an incomplete phase of lupus lymphadenitis (LL); however, the histologic findings differ. ${ }^{1-3,7} \mathrm{~A}$ lag time of 10 months to 3 years has been observed between the diagnosis of KFD and the subsequent onset of SLE. ${ }^{3}$ Regular follow-up visits are

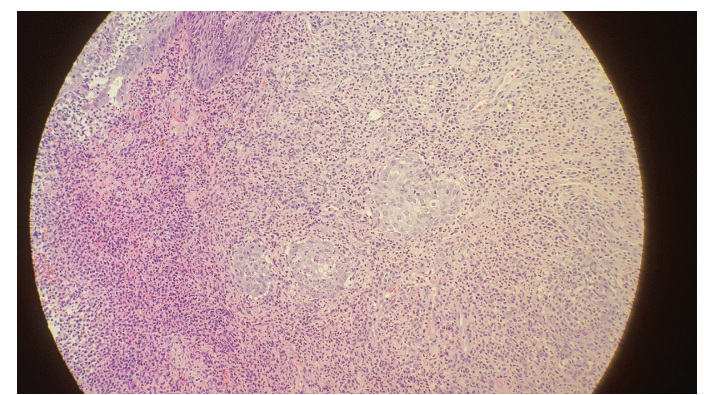

Figure 4.

This shave biopsy of the patient's posterior labia minora revealed brisk dermal neutrophilic infiltrate; her sebaceous glands were noted to be very edematous. These findings were nonspecific. required for patients with KFD, with the goal of early detection for potential relapses and onsets of SLE. Even without the occurrence of SLE, these patients should still be followed at proper intervals, since recurrences of KFD itself can also continue to occur for many years. ${ }^{2}$

Our case illustrates that diagnosis relies heavily on the successful procurement and evaluation of histological tissue within the lymph node. ${ }^{8,9}$ There are several key characteristics to distinguish between KFD and LL on histology. It is commonly accepted that hematoxyphilic bodies, DNA deposits in the walls of the vessels, and areas of vasculitis surrounding the necrotic foci are most representative of LL. ${ }^{1,2,8}$ Hematoxylin bodies are the most specific histologic feature of SLE lymphadenopathy. ${ }^{8}$ Features suggestive of KFD include geographic necrosis, karyorrhectic fragments, absence of neutrophils/eosinophils. ${ }^{1,2,8}$ Histological examination also exhibits numerous CD68+/myeloperoxidase (MPO)+ histiocytes, CD68+/ CD123+ plasmacytoid dendritic cells, and a minority of small- to large-sized CD8+lymphocytes and immunoblasts. ${ }^{11}$

As mentioned, this patient was initially diagnosed with the 2012 criteria at the time of evaluation. ${ }^{5}$ With application of the updated 2019 criteria, ${ }^{6}$ it became clear that our patient developed the 2 diseases concurrently. Whether or not the 2 conditions amalgamate into a common disease spectrum is widely disputed. ${ }^{1}$ Some have argued that this may be a prodromal form of lupus as opposed to a distinct disease. ${ }^{9}$ Additionally, it is not clear whether KFD cases associated with lupus skin disease are true KFD or a histopathologic feature of SLE. Nonspecific cutaneous manifestations like the nodules in our patient have been observed in up to $40 \%$ of cases, which further complicates diagnosis. ${ }^{10}$ It is recommended to obtain a skin biopsy whenever possible to differentiate KFD from SLE skin lesions. ${ }^{10}$ Our patient's lesions had resolved at the time of presentation, rendering that impossible.

A primary limitation is that the pathological features of KFD and LL show significant overlap. ${ }^{3}$ The nature of the clinical and pathophysiological relationships 
between KFD and SLE remain a matter of debate. ${ }^{3}$ Whether KFD can be considered an atypical manifestation of SLE remains disputed. ${ }^{3}$ Despite this, it has been repeatedly cited that the basis of diagnosis relies on histological examination of the lymph nodes. ${ }^{1,3}$ The literature's emphasis on this advanced testing supports the importance of a thorough physical examination with regularly scheduled follow-up for early detection of new onset lymphadenopathy that would present a target for biopsy should patients progress from KFD to SLE.

Another key message communicated to us through this clinical encounter is the vital role of the palpatory examination in discovering underlying pathology and the potential role of CR for discovering early disease manifestations. CR results were a key consideration in advocating for further diagnostic evaluation in our patient, and no known device has been developed that exceeds the tactile sensitivity of the human hand. ${ }^{12}$ Osteopathic structural examinations can be essential to discovering underlying acute inflammation and subsequent visceral dysfunction. ${ }^{4,12,13}$ Interestingly, the patient's CR may have corresponded to visceral dysfunction within the regional lymph nodes of the neck. ${ }^{4,13} \mathrm{CR}$ are manifested by gangliform contractions, which are believed to be congestions within fascia due to lymph stasis secondary to visceral dysfunction. ${ }^{4,13}$ Central to the pathophysiology of KFD is involvement of the lymph nodes. Acute inflammation is known to disrupt the homeostatic process in the interstitium and dramatically increase the burden on the lymphatic system. ${ }^{13}$

Given the importance of proper interval follow-up for KFD patients for development of SLE, osteopathic physicians may consider CR as a part of a screening or comprehensive osteopathic physical examination. Key features of $\mathrm{CR}$ are reviewed in Figure 2. ${ }^{4} \mathrm{CR}$ may imply dysfunction of an organ system advancing the physician to pursue potential diagnostic imaging and subsequent biopsy. ${ }^{4}$ A previous study ${ }^{14}$ evaluated the association between somatic dysfunction and abnormal endoscopic findings. Recent literature has postulated that osteopathic indicators, specifically $\mathrm{CR}$, may be valuable in detecting increased sympathetic tone before becoming physiologically evident; for example, a study ${ }^{15}$ regarding women with polycystic ovary syndrome (PCOS) suggested that earlier detection may represent an important window of intervention and possibly mitigate symptoms and sequalae associated with the disease process. Successful treatment of CR with manipulation and other forms of osteopathic manipulative treatment remains to be evaluated. Perhaps the largest limitation to studying these items in our patient is lack of disease prevalence.

Although rare, KFD is an important entity for clinicians to be aware of because of its nonspecific symptoms, arduous diagnosis, and potential progression to SLE. ${ }^{16}$ This may be deadly if not diagnosed properly, as SLE requires aggressive immunosuppressive measures. Patients with SLE have mortality rates ranging from 2 to 5 times higher than that of the general population. ${ }^{17,18}$ Conversely, KFD is generally managed with supportive measures such as antipyretics, though some patients may benefit from hydroxychloroquine with or without steroids. ${ }^{3,16,19}$ The basis of its diagnosis relies on the histological examination of lymph nodes, which typically reveals necrosis surrounded by histiocytes with crescentic nucleus, immunoblasts and plasma cells, and absence of neutrophils. ${ }^{1,3}$

\section{Conclusions}

In this patient, the careful palpatory examination of the lymph nodes and CR were early indicators of underlying acute inflammation and were essential to advocate further invasive testing in this patient, which revealed evidence of this rare disease. Regularly scheduled evaluations for early detection of amendable targets for biopsy are critical to detect progression from KFD to SLE. The diagnosis relies heavily on successful procurement and evaluation of histological tissue within the lymph node. 


\section{Acknowledgment}

The authors would like to thank Fernando Silva, MD for contributing to the care of this patient.

\section{Author Contributions}

Both authors provided substantial contributions to conception and design, acquisition of data, or analysis and interpretation of data; both authors drafted the article or revised it critically for important intellectual content; both authors gave final approval of the version of the article to be published; and both authors agree to be accountable for all aspects of the work in ensuring that questions related to the accuracy or integrity of any part of the work are appropriately investigated and resolved.

\section{References}

1. Baenas D, Diehl F, Haye Salinas M, Riva V, Diller A, Lemos P. Kikuchi-Fujimoto disease and systemic lupus erythematosus. Int Med Case Rep J. 2016;9:163-167. doi:10.2147/IMCRJ.S106396

2. Behdadnia A, Allameh SF, Gharabaghi MA, et al. Systemic kikuchi-fujimoto disease bordering lupus lymphadenitis: a fresh look? Intractable Rare Dis Res. 2016;5(4):301-305. doi:10.5582/ irdr.2016.01055.

3. Di Lernia V, Bajocchi G, Piana S. Subacute cutaneous lupus erythematosus onset preceded by Kikuchi-Fujimoto disease. Dermatol Pract Concept. 2014;4(1):47-49. doi:10.5826/ dpc.0401a06

4. Fossum C, Kuchera ML, Devine WH, Wilson K. 52G: Chapman's Approach. In: Chila A, Ed. Foundations of Osteopathic Medicine. LWW; 2011. 853-855. ISBN-13: 978-0781766715

5. Petri M, Orbai AM, Alarcon GS, et al. Derivation and validation of the systemic lupus international collaborating clinics classification criteria for systemic lupus erythematosus. Arthritis Rheum. 2012;64:2677-2686. doi:10.1002/art.34473.

6. Aringer M, Costenbader K, Daikh D, et al. 2019 European league against rheumatism/american college of rheumatology classification criteria for systemic lupus erythematosus. Ann Rheum Dis. 2019;78 (9):1151-1159. doi:10.1136/annrheumdis-2018-214819

7. Atarashi K, Yoshimura N, Nodera H, Tsukimoto K, Beppu H, Kanayama M. Recurrent histiocytic necrotizing lymphadenitis (kikuchi's disease) in a human t lymphotropic virus type I carrier. Internal Medicine. 1996;35(10):821-825. doi:10.2169/internalmedicine.35.821.
8. Perry AM, Choi SM. Kikuchi-fujimoto disease: a review. Arch Pathol Lab Med. 2018;142(11):1341-1346. doi:10.5858/arpa.2018-0219-RA

9. Hu S, Kuo TT, Hong HS. Lupus lymphadenitis simulating Kikuchi's lymphadenitis in patients with systemic lupus erythematosus: a clinicopathological analysis of six cases and review of the literature. Pathol Int. 2003;53(4):221-226. doi:10.1046/j.1320-5463.2003.01458.x

10. Kuo TT. Cutaneous manifestation of dikuchi's histiocytic necrotizing lymphadenitis. Am J Surg Pathol. 1990;14(9):872-876. doi:10.1097/ 00000478-199009000-00009

11. Pepe F, Disma S, Teodoro C, Pepe P, Magro G. Kikuchi-fujimoto disease: a clinicopathologic update. Pathologica. 2016;108 (3):120-129.

12. Ehrenfeuchter WC, Kappler RE. Chapter 33: Section 1. In: Chila A, Foundations of Osteopathic Medicine. LWW; 2011.

13. Ettlinger $\mathrm{H}$, Willard $\mathrm{FH}$. Chapter 12 : anatomy and physiology of the lymphatic system. In: Chila A, Foundations of Osteopathic Medicine. LWW; 2011.

14. Snider KT, Schneider RP, Snider EJ, et al. Correlation of somatic dysfunction with gastrointestinal endoscopic findings: an observational study. J Am Osteopath Assoc. 2016;116(6):358-369. doi:10.7556/ jaoa.2016.076

15. Davis SE, Hendryx J, Bouwer S, et al. Correlation between physiologic and osteopathic measures of sympathetic activity in women with polycystic ovary syndrome. J Am Osteopath Assoc. 2019;119(1):7-17. doi:10.7556/jaoa.2019.004

16. Dumas G, Prendki V, Haroche J, et al. Kikuchi-fujimoto disease: retrospective study of 91 cases and review of the literature [published correction appears in Medicine (Baltimore). 2014;93(24):414]. Medicine (Baltimore). 2014;93(24):372-382. doi:10.1097/ MD. 0000000000000220

17. Borchers AT, Keen CL, Shoenfeld Y, Gershwin ME. Surviving the butterfly and the wolf: mortality trends in systemic lupus erythematosus. Autoimmun Rev. 2004;3(6):423-453. doi:10.1016/j. autrev.2004.04.002

18. Singh RR, Yen EY. SLE mortality remains disproportionately high, despite improvements over the last decade. Lupus. 2018;27 (10):1577-1581. doi:10.1177/0961203318786436

19. Honda $\mathrm{F}$, Tsuboi $\mathrm{H}$, Toko $\mathrm{H}$, et al. Recurrent kikuchi-fujimoto disease successfully treated by the concomitant use of hydroxychloroquine and corticosteroids. Intern Med. 2017;56(24):3373-3377. doi:10.2169/ internalmedicine.9205-17

๑) 2020 American Osteopathic Association 